\title{
Taxon-specific metagenomics of Trichoderma reveals a narrow community of opportunistic species that regulate each other's development
}

\author{
Correspondence \\ Irina S. Druzhinina \\ druzhini@mail.zserv.tuwien.ac.at
}

Received 28 June 2011

Revised 9 September 2011

Accepted 4 November 2011

\author{
Martina A. Friedl and Irina S. Druzhinina
}

Research Area of Gene Technology and Applied Biochemistry, Institute of Chemical Engineering, Vienna University of Technology, Getreidemarkt 9-1665, A-1060 Vienna, Austria

\begin{abstract}
In this paper, we report on the in situ diversity of the mycotrophic fungus Trichoderma (teleomorph Hypocrea, Ascomycota, Dikarya) revealed by a taxon-specific metagenomic approach. We designed a set of genus-specific internal transcribed spacer (ITS) 1 and ITS2 rRNA primers and constructed a clone library containing 411 molecular operational taxonomic units (MOTUs). The overall species composition in the soil of the two distinct ecosystems in the Danube floodplain consisted of 15 known species and two potentially novel taxa. The latter taxa accounted for only $1.5 \%$ of all MOTUs, suggesting that almost no hidden or uncultivable Hypocrea/Trichoderma species are present at least in these temperate forest soils. The species were unevenly distributed in vertical soil profiles although no universal factors controlling the distribution of all of them (chemical soil properties, vegetation type and affinity to rhizosphere) were revealed. In vitro experiments simulating infrageneric interactions between the pairs of species that were detected in the same soil horizon showed a broad spectrum of reactions from very strong competition over neutral coexistence to the pronounced synergism. Our data suggest that only a relatively small portion of Hypocrea/Trichoderma species is adapted to soil as a habitat and that the interaction between these species should be considered in a screening for Hypocrea/Trichoderma as an agent(s) of biological control of pests.
\end{abstract}

\section{INTRODUCTION}

Trichoderma species are one of the most frequently isolated conidial fungi (teleomorph Hypocrea, Hypocreales, Ascomycota, Dikarya). They have been identified from a diverse range of natural and artificial substrata, which demonstrates their high opportunistic potential and adaptability to various ecological conditions (Druzhinina et al., 2011). The exploitation of the latter properties of Trichoderma in biotechnology and agriculture mean that the genus has been well studied and it has been the focus of numerous -omic studies (see Lorito et al., 2010 for a

\footnotetext{
Abbreviations: ciPCR, culture-independent PCR; ITS, internal transcribed spacer; MOTU, molecular operational taxonomic unit.

The GenBank/EMBL/DDBJ accession numbers for the sequences identified in this study are: T. harzianum, G0981644, G0981645, GU060097-GU060105; T. cerinum, GU060106, GU060107; T. pleuroticola, GU060108, GU060109; H. alni, GU060110; H. virens, GU060111; Trichoderma sp. MOTU 1A 64, GU060112-GU060117; T. brevicompactum, GU060118-GU060120; H. pachybasiodes, GU060121; uncultured H. pachypallida, GU060122-GU060125; T. Iongibrachiatum, GU060126-GU060128; H. schweinitzii, GU060129; T. asperellum, GU060130-GU060137; Trichoderma sp. MOTU 2B 48, GU060138, GU060139.
}

Three supplementary figures and two supplementary tables are available with the online version of this paper. review), including the three complete genome sequences recently released for public access: Hypocrea jecorina (Martinez et al., 2008), H. virens and $H$. atroviridis (Kubicek et al., 2011). The comparative analysis of these genomes with each other and other Ascomycota revealed that the outstanding antagonistic ability of Trichoderma spp. against plant-pathogenic fungi (known as necrotrophic hyperparasitism or mycoparasitism) is the ancestral state for the genus (Kubicek et al., 2011). Several studies have documented that Trichoderma harzianum sensu lato, T. asperellum and T. asperelloides are highly rhizosphere competent and are able to stimulate growth and immune defence of plants (reviewed by Harman et al., 2004).

The current diversity of the holomorphic genus Hypocreal Trichoderma is reflected in approximately 160 species (Samuels, 2005; Druzhinina et al., 2006; Kubicek et al., 2008, NCBI Taxonomy Browser, February 2011), the majority of which have been recognized on the basis of DNA sequence analysis and molecular phylogeny of pure cultures and/or herbaria specimens. A multigene phylogeny established in several studies (see Kubicek et al., 2008, for a review and Jaklitsch, 2011, for updates) allowed the development of reliable tools for molecular species identification based on DNA barcoding, i.e. the analysis of DNA sequence polymorphism in the internal transcribed spacers 1 and 2 (ITS1 
and 2) of the rRNA operon and other loci (Druzhinina et al., 2005; Kopchinskiy et al., 2005, http://www.isth.info).

The complete inventory of teleomorph-forming species in Central Europe indicated that there are 75 species (Jaklitsch, 2009, 2011). In addition to this, about 12 anamorphic species (for which no sexual stages are known) were reported in surveys of European soils and in taxonomic studies, as described by Wuczkowski et al. (2003), Kraus et al. (2004), Samuels et al. (2006b), Jaklitsch et al. (2006a, b), KomonZelazowska et al. (2007), Hagn et al. (2007), Druzhinina et al. (2008), Migheli et al. (2009), Zachow et al. (2009) and Meincke et al. (2010). Thus, the total number of Hypocreal Trichoderma species identified so far in Europe may be about 100 .

The major ecological niche for Hypocrea/Trichoderma may be deduced from the distribution of holomorphic species (when both teleomorphic and anamorphic stages are observed), which constitute the major genetic pool for the genus; they are associated with dead wood in different stages of its decay and with sporocarps of other fungi (Jaklitsch, 2009). Trichoderma species were initially believed to be among the dominant taxa inhabiting soil ecosystems (Klein \& Eveleigh, 1998). However, this statement was not supported by the application of high-throughput sequencing methods to study the cultivation-independent fungal diversity in soil. These studies did not reveal that Trichoderma was abundant, listing it among the minor taxa (Buée et al., 2009; Lim et al., 2010).

Thus, molecular ecology and genomics of the genus indicate that the presence of Hypocrea/Trichoderma in soil, where it may either be a saprotroph or establish various associations with plants and animals (biotrophy), could be driven by the general mycotrophy, including various forms of mycoparasitism, combined with broad environmental opportunism (Rossman et al., 1999; see Druzhinina et al., 2011 for a review).

The aim of this research was to use a taxon-specific metagenomic approach to explore the diversity of Hypocreal Trichoderma in a soil profile and to identify the factors which control the size/occurrence of its infrageneric communities.

\section{METHODS}

Sampling sites. Two sampling sites were chosen in the River Danube National Park 'Nationalpark Donau-Auen' (Austria). They were located 500 metres apart representing the essentially different biotopes (Table 1). The beech forest site $\left(+48^{\circ} 9^{\prime} 28 \mathrm{~N}\right.$, $+16^{\circ} 32^{\prime} 9 \mathrm{~W}$, altitude $162 \mathrm{~m}$ ) belongs to the hard wood riparian forest which is situated above the seasonal Danube overflow level (approx. $3 \mathrm{~m}$ above the water level). The aspen forest site $\left(+45^{\circ} 30^{\prime} 43 \mathrm{~N},+73^{\circ} 32^{\prime} 44 \mathrm{~W}\right.$, altitude $\left.141 \mathrm{~m}\right)$ represents the softwood riparian forest regularly flooded during the seasonal Danube overflows. A detailed botanical description of both ecosystems is given in Table 1.

Soil sampling and detection of soil properties. In both ecosystems, pits about $100 \mathrm{~cm}$ deep were made and soil samples
( 200 g) were taken from each soil horizon using a sterile knife. The soil samples were immediately separated from roots and large particles, and samples were air-dried and sieved through a metal mesh to collect fine particles $<2 \mathrm{~mm}$ ('fine earth fraction'). Thereafter, each soil sample was spread into a sterile tray and divided into four equally sized fragments, two of which were discarded while the remaining two were thoroughly mixed and again spread on the same tray for subsequent subsampling (Robertson et al., 1999). Finally $50 \mathrm{~g}$ of each soil was stored at $-20{ }^{\circ} \mathrm{C}$ for further molecular and chemical investigations.

Soil classification and the detection of soil horizons were done directly at the two sampling spots. The soil colour was defined using a standard colour scale for soil science (Munsell Soil Colour Charts, US Department of Agriculture). The horizons were visually distinguished based on their colour and were later differentiated based on their chemical properties. All chemical analyses were performed using the fine earth fraction. To measure $\mathrm{pH}, 1 \mathrm{~g}$ soil was suspended in $100 \mathrm{ml}$ $1 \mathrm{M} \mathrm{KCl}$ and shaken for $1 \mathrm{~h}$. Finally, $\mathrm{pH}$ was determined with a glass electrode. The total nitrogen content was determined according to the Kjeldahl method (see Batjes, 1996) on a Vapodest 30 (Gerhardt). The total organic carbon content was measured using the Liechtenfelder method (see Batjes, 1996), which oxidizes carbon with potassium dichromate and photometrically quantifies the generated $\mathrm{Cr}^{3+}$ (DIN 19684).

Development of genus-specific primers. The genus-specific primers were developed based on the master alignment of ITS1 and 2 from 88 Hypocrea and Trichoderma reference strains (Druzhinina et al., 2005) complemented by the new species described since that time (Jaklitsch et al., 2005, 2006a, b; Overton et al., 2006; Samuels et al., 2006b; Komon-Zelazowska et al., 2007; Jaklitsch et al., 2008; Jaklitsch, $2009,2011)$. All primers are reverse primers and are complementary to the forward primer ITS5 (5'-GGAAGTAAAAGTCGTAACAAGG-3') (Table 2). The position of primers is shown on htttp://www.ISTH.info/ methods/method.php?method_id=12. The verification of primer specificity was done with reference cultures described by Druzhinina et al. (2005). The general test of possible unspecific annealing was done by sequence similarity searches against NCBI GenBank (May 2006) adjusted for short query sequences.

Isolation of DNA and culture-independent PCR (ciPCR). A representative subsample of the fine soil fraction $(1 \mathrm{~g})$ was thawed and dried overnight in a drying chamber at $90{ }^{\circ} \mathrm{C}$. Afterwards, the individual soil samples were well homogenized and DNA was extracted using a FastDNA Spin kit for soil (MP Biomedicals). The DNA was then used as a template for ciPCR with Hypocreal Trichoderma-specific rRNA primers as listed in Table 2. ciPCR products of all six primers were combined and purified using QiaQuick PCR purification kit (Qiagen).

ciPCRs were carried out in a total volume of $50 \mu \mathrm{l}$ containing $2.5 \mathrm{mM}$ $\mathrm{MgCl}_{2}, 10 \mathrm{mM}$ Tris/HCl pH 9.0, $50 \mathrm{mM} \mathrm{KCl}, 0.1 \%$ (v/v) Triton X100, $0.4 \mu \mathrm{M}$ each primer, $0.2 \mathrm{mM}$ each dNTP and 0.5 units Taq Polymerase (Promega). The amplification program consisted of 1 min initial denaturation $\left(94^{\circ} \mathrm{C}\right)$, 30 cycles of amplification $(1 \mathrm{~min}$ $94{ }^{\circ} \mathrm{C}, 1 \mathrm{~min} 52{ }^{\circ} \mathrm{C}, 1 \mathrm{~min} 72{ }^{\circ} \mathrm{C}$ ) and a final extension period of 7 min at $72{ }^{\circ} \mathrm{C}$.

Amplification products were visualized on $1 \%$ TAE agarose gels, and the ciPCR amplicons, at $600 \mathrm{~kb}$, were excised, repurified using QiaQuick gel excision kit (Qiagen) and suspended in $20 \mu \mathrm{l}$ water.

Construction of clone libraries and sequencing. The ciPCR products were subcloned using the standard pGEMTeasy (Promega) procedure. At least 100 colonies were selected from each soil sample. Plasmids were extracted using a standard miniprep method. In order to determine whether the plasmid DNA was carrying the insert, the 
Table 1. Ecosystem description and soil properties

\begin{tabular}{|c|c|c|c|c|c|c|c|}
\hline & \multicolumn{4}{|c|}{ Beech forest site } & \multicolumn{3}{|c|}{ Aspen forest site } \\
\hline Type of ecosystem & \multicolumn{4}{|c|}{ Hardwood riparian forest patch } & \multicolumn{3}{|c|}{ Clearing of the soft wood riparian forest } \\
\hline Flooding frequency & \multicolumn{4}{|l|}{ Rare to never } & \multicolumn{3}{|c|}{ Regular } \\
\hline \multicolumn{8}{|l|}{ Botanical description } \\
\hline Trees & \multicolumn{4}{|l|}{ Tall, thick } & \multicolumn{3}{|l|}{ Moderately tall, thin } \\
\hline Dominant & \multicolumn{4}{|c|}{ Ulmus laevis, Populus canescens, Fraxinus excelsior } & \multicolumn{3}{|c|}{ P. alba, $P$. nigra, $P$. canescens } \\
\hline Rare & \multicolumn{4}{|c|}{ P. nigra, $P$. alba, Salix rubens } & \multicolumn{3}{|l|}{ S. rubens } \\
\hline Shrub and regeneration & \multicolumn{4}{|l|}{ Light } & \multicolumn{3}{|l|}{ Dense } \\
\hline Dominant & \multicolumn{4}{|l|}{ Crataegus monogyna } & \multicolumn{3}{|l|}{ Rubus idaeus } \\
\hline Rare & \multicolumn{4}{|c|}{ Populus sp., Acer sp., Salix sp. } & \multicolumn{3}{|c|}{ Quercus rubur, Populus sp. } \\
\hline Herbs & \multicolumn{4}{|c|}{ Lighted } & \multicolumn{3}{|l|}{ Dense } \\
\hline Dominant & \multicolumn{4}{|l|}{ Aegopodium podagraria } & \multicolumn{3}{|c|}{ Allium ursinum, Aegopodium podagraria } \\
\hline Rare & \multicolumn{4}{|c|}{ Salvia glutinosa, Poaceae, Cyperaceae } & \multicolumn{3}{|c|}{$\begin{array}{l}\text { Carex acuta, Urtica dioica, Epilobium sp., Salvia } \\
\text { glutininosa, Silidago gigantea }\end{array}$} \\
\hline Fallen trees & \multicolumn{4}{|l|}{ Abundant } & \multicolumn{3}{|l|}{ None } \\
\hline \multicolumn{8}{|l|}{ Soil properties } \\
\hline Litter layer & \multicolumn{4}{|l|}{ Thick, well developed } & \multicolumn{3}{|l|}{ Thin, undeveloped } \\
\hline Soil type (FAO) & Cambic fluvisol & & & & Calcaic fluvisol with a hi & evel of sandy & diments \\
\hline Soil moisture content & Moderate & & & & High & & \\
\hline Siltation & Moderate & & & & High & & \\
\hline Vertical profile & Well differentiated & & & & Well differentiated & & \\
\hline Horizon name & A0 & $\mathrm{A}$ & B & $\mathrm{C}$ & A & $\mathrm{BC}$ & $\mathrm{C}$ \\
\hline Thickness (cm; of $1 \mathrm{~m}$ section) & 5 & 10 & $40-50$ & $20+$ & 10 & $20-30$ & $50-60$ \\
\hline Soil colour & Very dark brown & Dark greyish & Greyish brown & Very dark greyish brown & Light olive brown & $\begin{array}{l}\text { Light olive } \\
\text { brown }\end{array}$ & $\begin{array}{l}\text { Light olive } \\
\text { brown }\end{array}$ \\
\hline Soil colour code (Munsell) & $10 \mathrm{YR} 2 / 2$ & $10 \mathrm{YR} 4 / 2$ & $2.5 Y 5 / 2$ & $2.5 \mathrm{Y} 3 / 2$ & $2.5 Y 5 / 3$ & & \\
\hline Relative root density & No roots & Very high & High & Moderate & High & Low & No roots \\
\hline Chemical characteristics & & & & & & & \\
\hline $\mathrm{pH}$ & 7.77 & 7.90 & 8.10 & 8.24 & 7.60 & 8.15 & 8.23 \\
\hline $\mathrm{C}(\%)$ & 8.16 & 2.38 & 1.82 & 2.50 & 6.52 & 1.04 & 2.51 \\
\hline $\mathrm{N}(\%)$ & 0.37 & 0.15 & 0.06 & 0.04 & 0.43 & 0.07 & 0.04 \\
\hline $\mathrm{C} / \mathrm{N}$ & 22.05 & 15.87 & 30.33 & 62.50 & 15.16 & 14.86 & 62.75 \\
\hline
\end{tabular}


Table 2. Genus- and species-specific PCR primers designed in this study

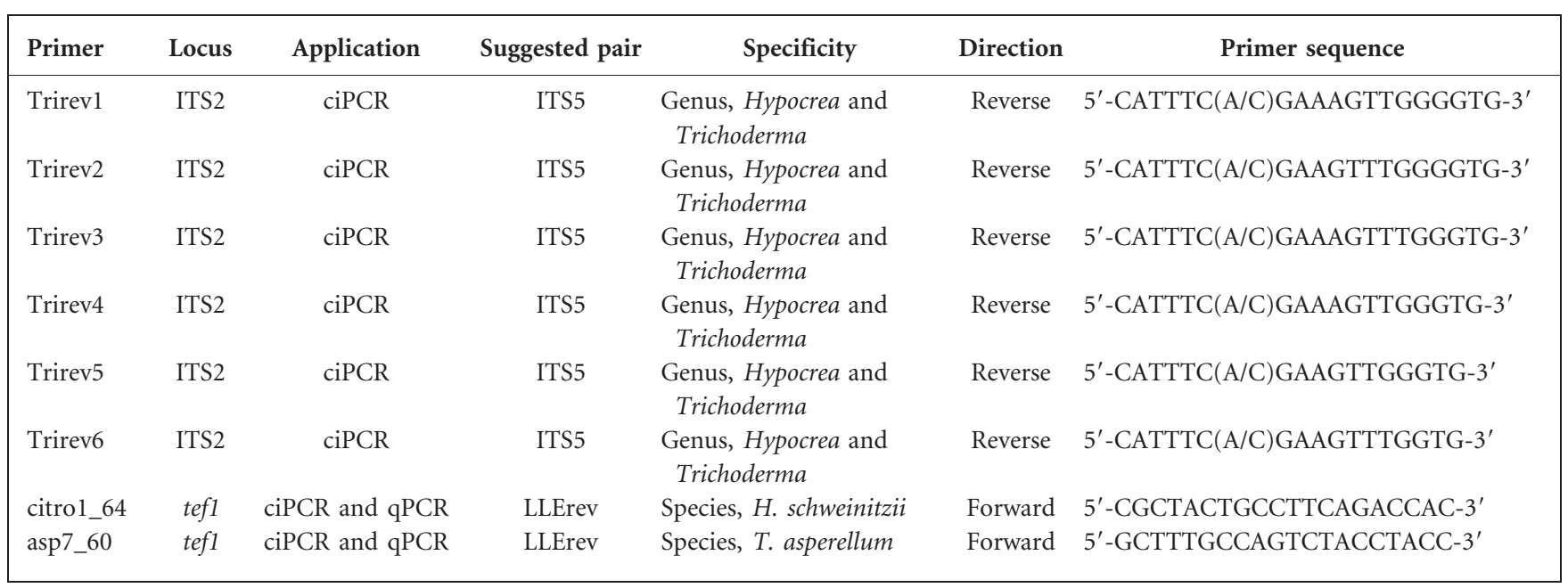

plasmid DNA was digested with 5 units of NotI and EcoRI (Fermentas). For positive samples, $0.5 \mu \mathrm{g}$ plasmid DNA was finally used for automated sequencing (Eurofins) from both directions.

Representative alleles for all species from each horizon have been deposited in GenBank (accession numbers are given in the footnote on page 1). The alignment matrix is available upon request.

Species identification and diversity assessment. All sequences were aligned in GeneDoc 2.6 (Nicholas \& Nicholas, 1997) using the guidance for Hypocrea/Trichoderma ITS1 and 2 alignment provided by Druzhinina et al. (2005), available online at http://www.isth.info/ tools/master.php. For species identification, the complete set of sequences was submitted to the DNA oligonucleotide barcode program TrichOKey (http://www.isth.info/tools/molkey/index.php; Druzhinina et al., 2005). All sequences contained the set of five genus-specific hallmarks and were therefore attributed to Hypocrea/ Trichoderma. Hence, tests for chimerical sequences were not required. All unusual ITS1 and 2 alleles have been further analysed by sequence similarity searches against NCBI GenBank, TrichoBLAST (Kopchinskiy et al., 2005) and the sequence database of the collection of fungal strains of Vienna University of Technology that currently contains more than 4000 Hypocrea/Trichoderma strains with 5500 core nucleotide sequences including ITS1 and 2. Based on individual mismatches found in the otherwise conserved areas of ITS1 and 2 (for example, genus-specific hallmarks or 5.8S rRNA gene, see Druzhinina et al., 2005), $20 \%$ of the sequences have been found to contain single sequencing errors. Four sequences contained polymorphic sites in the diagnostic regions of both ITS1 and 2 and therefore have been diagnosed as potentially new alleles (Trichoderma sp. MOTU 1A 64 for section Longibrachiatum and Trichoderma sp. MOTU 2B 48 for section Trichoderma).

Development and verification of species-specific tef1 primers for qPCR. In order to design species-specific qPCR primers, representative sequences of the fourth large intron of the tefl gene coding the elongation factor $1 \propto$ for the whole genus Hypocreal Trichoderma were retrieved from the multilocus database of phylogenetic markers (http://www.isth.info) and automatically aligned in CLUSTAL_X (Thompson et al., 1997). The representative tefl sequence of a target species was submitted to NCBI sequence similarity search tool (BLASTN) and all homologous vouchered sequences $(n \geqslant 20)$ attributed to the same species were retrieved and added to the initial alignment. Subsequently, species-specific diagnostic regions were manually selected for each target species so that they would contain the minimal level of infraspecific polymorphism. In parallel, the same alignments were used to design degenerate species-specific primers in HYDEN software (Linhart \& Shamir, 2005). The annealing temperature and secondary structure of oligonucleotides designed based on both approaches have been estimated using Gene Runner (Gene Runner 3.0 software) and SMS PCR Primer Stats tools http://www.bioinformatics.org/sms2/pcr primer_stats.html. The specificity of selected primers was first tested against the NCBI GenBank database (automatically optimized for short queries) and then verified by PCR (see Jaklitsch et al., 2006a for conditions) with reference DNA from pure cultures of all genetically close members and several members of the neighbouring clades. The resulting potentially species-specific oligonucleotides were tested for annealing efficiency by applying serial dilutions of a target DNA extract. Selectivity of the designed primers was verified by subcloning the PCR product obtained from the soil DNA extract. Around 40 oligonucleotides have been synthesized to hit the diversity of the most frequent temperate Hypocrea/Trichoderma species but only two primers targeting T. asperellum and H. schweinitzii (Table 2) showed high specificity, selectivity and appropriate efficiency $(\geqslant 80 \%)$ for application to environmental samples.

Quantitative PCR assessment. Quantitative PCR (qPCR) amplification was carried out by using the iQ 5 Real-Time PCR detection system (Bio-Rad) in a $25 \mu \mathrm{l}$ reaction containing $12.5 \mu \mathrm{l}$ iQ SYBR Green Supermix (Bio-Rad), each primer at $250 \mathrm{nM}$ and sample, corresponding to an initial concentration of $0.5 \mu \mathrm{l}$ total DNA. Amplification was carried out with the following PCR program: initial denaturation for 3 min at $95{ }^{\circ} \mathrm{C}$, followed by 45 cycles of $95{ }^{\circ} \mathrm{C}$ for $15 \mathrm{~s}, 54.0{ }^{\circ} \mathrm{C}($ tefl 1$)$ for $20 \mathrm{~s}$, and $72{ }^{\circ} \mathrm{C}$ for $20 \mathrm{~s}$. Successful amplification was verified by determining the melting temperature and by agarose gel electrophoresis. For each species, a series of dilutions was performed to assess the efficiency of the PCR. The results of the real-time PCR were analysed with the iQ 5 optical system software (Bio-Rad). Using the PCR base line subtracted mode, the threshold cycle was calculated for all samples and the amplification efficiency for each primer was determined.

In vitro pair-wise interactions. Strains were cultivated at room temperature and ambient illumination without direct sunlight in $100 \mathrm{ml}$ Erlenmeyer flasks with $50 \mathrm{ml} 3 \%$ malt extract for 5 days without shaking. The mycelia developed mats on the surface of the liquid. Thereafter, the biomass was filtered out in aseptic conditions and the remaining cultivation solution was centrifuged at $25155 \mathrm{~g}$ for $10 \mathrm{~min}$ to sediment the remaining spores. The 
supernatant was then filtered through $0.2 \mu \mathrm{m}$ sterile cellulose acetate filter (Whatman) and used for the experiment. Aliquots of the final culture supernatant $(50 \mu \mathrm{l})$ were then pipetted into 96-well microplates with a flat bottom profile and inoculated with $50 \mu \mathrm{l}$ conidia suspension of the tested strain. Conidia of these were obtained by growing the strains on $3 \%(\mathrm{w} / \mathrm{v})$ malt extract agar for 7 days at room temperature and in ambient light. Conidia were harvested by rolling the sterile cotton swabs against the surface of the Petri plate and transferred to sterile $3 \%$ malt extract. Spore concentration was standardized to $5 \times 10^{5} \mathrm{ml}^{-1}$ by turbidity measurements at $590 \mathrm{~nm}$. Each microplate was inoculated with conidial suspension from one species. Microplates were then incubated at $25{ }^{\circ} \mathrm{C}$ in darkness for 8 days. Mycelial growth was measured every $24 \mathrm{~h}$ using a Biolog microplate reader by recording $\mathrm{OD}_{750}$. Conidiation was assessed visually after $192 \mathrm{~h}$ incubation. Complete experiments were repeated in eight linked replications (on one microplate) and in at least two independent repeats.

Statistical analysis. Cultivation-independent diversity and species richness of Hypocrea/Trichoderma were assessed in EstimateS 8.2. Rarefaction curves were computed for each soil profile. The number of species was quantified for 100 random combinations of $1-n$ sequences and also by performing 100 bootstrap pseudoreplicates implemented in EstimateS (Colwell, 2005).

Statistical analyses of metagenomic data and in vitro infrageneric interactions were carried out using the Statistica 6.1 (StatSoft) software package using basic data exploration tools, correlation matrices, variance analyses and multifactorial techniques (factor analysis and cluster analysis). Discrete colour plots representing the results of pair-wise interactions between different Hypocreal Trichoderma strains were constructed based on the results of a twoway joining cluster analysis implemented in Statistica 6.1 with consequent reordering of both variables and cases, in order to reflect phylogenetic groups inside the sample.

\section{RESULTS}

\section{The pedogenesis of both sites is strongly influenced by the river}

Two sampling sites representing essentially different biotopes (Table 1) in a riparian forest were selected in the River Danube National Park, south-east of Vienna, Austria. We performed a $1 \mathrm{~m}$ deep vertical soil cut into both ecosystems in places that are equally distanced from surrounding big trees and shrubs and which therefore do not represent exclusive rhizospheres of any plant species.

The major difference between the two soil cuts was in the presence of the thick $(\min .5 \mathrm{~cm}$ ) soil litter layer (FAO horizon $\mathrm{A} 0$ ) in the beech site which was absent in the aspen forest. Instead, the latter site was covered by a dense herbal layer dominated by the blossoming Alnus urcinum with several codominant herbal species (see Table 1). Correspondingly, the beech forest soil profile was evenly penetrated by roots from different plants while in the aspen forest a high root density was only observed in the upper horizon.

The pedogenesis of both sites is strongly influenced by the river and results in formation of fluvisols (FAO classification: J; FAO, 1998) with a high level of calcaric soil material and sedimentation. The flooded soil in the aspen forest contains significantly more moisture than the beech forest (Table 1). Both sites were characterized by well-developed soil profiles and the presence of at least three horizons in FAO nomenclature. The soil of the beech forest was characterized by three clear horizons: A, B and C. At the aspen forest, the B layer contained little alteration products and was mixed with the parent material; therefore, the horizons at this sampling spot were classified as $\mathrm{A}, \mathrm{BC}$ and $\mathrm{C}$ (Table 1). The chemical properties of the soil are detailed in Table 1 .

\section{CiPCR revealed restricted diversity of Hypocrea/ Trichoderma in temperate soil}

We designed a set of genus-specific ciPCR reverse primers Trirev (1-6) (5'-CATTTCMG $\left[\mathrm{A}_{2} / \mathrm{A}_{3}\right] \mathrm{G}\left[\mathrm{T}_{2} / \mathrm{T}_{3}\right]\left[\mathrm{G}_{2} / \mathrm{G}_{3} / \mathrm{G}_{4}\right] \mathrm{TG}-$ $3^{\prime}$, melting temperature $61{ }^{\circ} \mathrm{C}$; Table 2) at the $3^{\prime}$-end of the ITS2 of the rRNA gene cluster (Table 2). The position of the primers is illustrated on the ISTH website: http://www.isth. info/methods/method.php?method_id=12. When applied together with the ITS5 forward primer (White et al., 1990), these primers amplified a 510-540 bp fragment covering the complete diagnostic area of ITS1 and 2 including all five genus-specific hallmarks (Druzhinina et al., 2005).

Application of the ITS5/Trirev primer pair in a ciPCR with DNA extracts from soil samples showed different results for individual primers and also differing efficiency of the Trirev primers in samples from different horizons. The highest affinity of Trirev primers was detected for horizon A followed by the two other soil horizons of the beech forest site (Supplementary Fig. S1, available with the online version of this paper). PCR efficiency in the soil of the aspen forest was lower. The pooled ciPCR products of ITS5/Trirev obtained for each soil horizon were used for subsequent clone libraries.

In total, 411 ITS1 and two rRNA molecular taxonomic units (MOTUs) were recovered (Fig. 1). All sequences had diagnostic genus-specific hallmarks (Druzhinina et al., 2005), suggesting that the Trirev primers were highly selective. All MOTUs were identified as being one of 15 known species or two putatively novel taxa (Table 3). The rarefaction curve suggested that the species richness was close to saturation, as an additional 100 MOTUs revealed only one or two additional species (Supplementary Fig. S2, available with the online version of this paper).

MOTU frequencies were used to calculate the diversity index as an indirect quantitative measure of community composition. The dominant species in both sites (54 and $28.6 \%$ for beech and aspen forests, respectively) was $T$. asperellum sensu stricto (Samuels et al., 2010).

The beech forest soil was co-dominated by T. harzianum sensu stricto (Druzhinina et al., 2010b), T. rossicum, $H$. 'pseudoharzianum' (Druzhinina et al., 2010b, widely known as $T$. harzianum complex) and $H$. pachypallida (Jaklitsch, 2011) which contributed $11,9,8$ and $6 \%$, respectively, of the total diversity at this location. Sequences of the $T$. longibrachiatum-H. orientalis species pair (Druzhinina et al., 


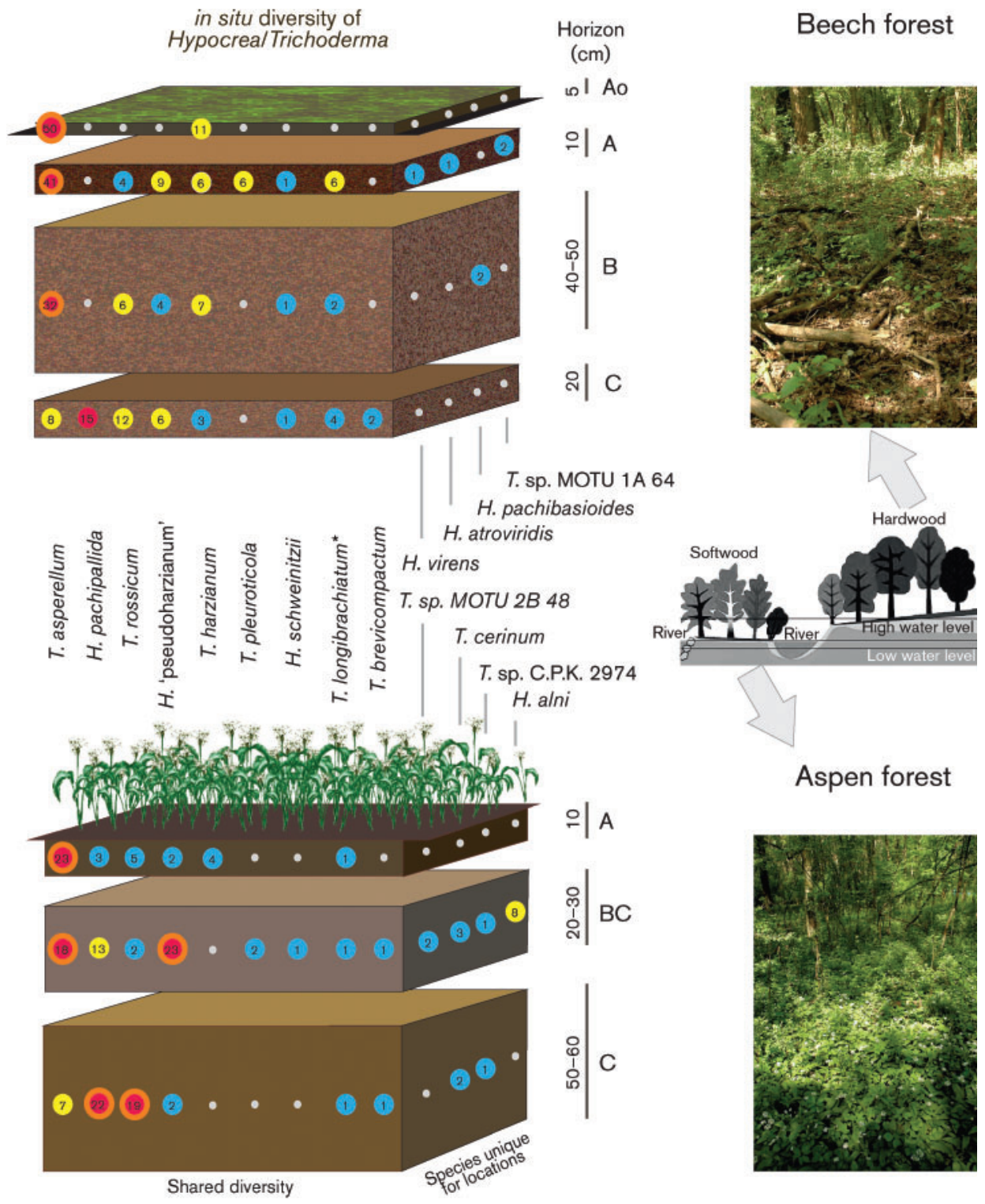

Fig. 1. In situ diversity of Hypocrea/Trichoderma in the vertical profiles of two soil cuts in a hardwood beech and a softwood aspen forest. Numbers in coloured circles indicate the number of MOTUs of each species recovered; red, yellow and blue circles correspond to dominant, subdominant and rare species, respectively. The schematic profile of the flood plain ecosystem of the River Danube (middle) and images of the sampling sites (top and bottom) are shown to the right. *, T. longibrachiatum-H. orientalis species pair.

2008 ) added $5 \%$ and could be considered as a subdominant taxon (Fig. 1). T. pleuroticola (2.5\%), H. schweinitzii (1.2\%), T. brevicompactum $(0.8 \%), H$. pachybasioides $(0.8 \%)$ and taxonomic units of a putative novel species from section Longibrachiatum Trichoderma cf. sp. nov. MOTU 1A 64 $(0.8 \%)$ were rare. MOTUs of $H$. atroviridis and $H$. virens were recovered with a frequency $<0.5 \%$.

A qualitatively similar but quantitatively different species composition was observed in the aspen forest (Fig. 1): the dominant $T$. asperellum was followed by co-dominant $H$. pachypallida (23\%), H. 'pseudoharzianum' (16\%) and T. rossicum (15.5\%). The subdominant species H. alni (5\%) and T. cerinum (3\%) were present in significantly lower amounts. T. harzianum sensu stricto $(2.4 \%), T$. longibrachiatum- $H$. orientalis species pair $(1.8 \%), T$. pleuroticola $(1.2 \%)$, T. brevicompactum (1.2\%), Trichoderma sp. C.P.K. 2974 (I. S. Druzhinina, unpublished data) (1.2\%) and a putative novel species from section Trichoderma sp. nov. MOTU 2B 48 were rare; the ITS sequence of $H$. schweinitzii was recovered only once.

Thus, among 17 recovered taxa, we detected nine species present at both sites and four species unique to each 


\section{Table 3. In situ diversity of Hypocrea/Trichoderma in vertical soil profile and its correlation with soil properties}

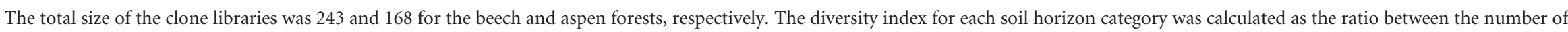

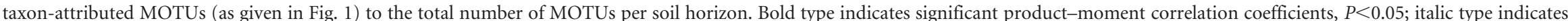
significant coefficients for repressed species. TF, Total frequency; LF, local frequency.

\begin{tabular}{|c|c|c|c|c|c|c|c|c|c|c|c|c|c|c|c|c|c|}
\hline \multirow[t]{3}{*}{ Species } & \multirow[t]{3}{*}{ TF $(\%)$} & \multicolumn{5}{|c|}{ Beech forest } & \multicolumn{4}{|c|}{ Aspen forest } & \multicolumn{7}{|c|}{ Correlation coefficients } \\
\hline & & \multirow[t]{2}{*}{ LF (\%) } & \multicolumn{4}{|c|}{ Soil horizon } & \multirow[t]{2}{*}{ LF (\%) } & \multicolumn{3}{|c|}{ Soil horizon } & \multirow{2}{*}{$\begin{array}{c}\text { Soil } \\
\text { horizon }\end{array}$} & \multirow[t]{2}{*}{$\mathrm{pH}$} & \multirow[t]{2}{*}{ C (\%) } & \multirow[t]{2}{*}{ N (\%) } & \multirow[t]{2}{*}{$\mathrm{C} / \mathrm{N}$} & \multirow{2}{*}{$\begin{array}{c}\text { Root } \\
\text { density }\end{array}$} & \multirow{2}{*}{$\begin{array}{c}\text { Depth } \\
(\mathrm{cm})\end{array}$} \\
\hline & & & A0 $(61)^{\star}$ & A (77) & B (54) & C (51) & & A (38) & BC (75) & C (55) & & & & & & & \\
\hline T. asperellum & 43.6 & 53.9 & 0.206 & 0.169 & 0.132 & 0.033 & 28.6 & 0.137 & 0.107 & 0.042 & -1.0 & -0.8 & - & - & -0.8 & - & 0.9 \\
\hline H. pachypallida & 12.9 & 6.2 & - & - & - & 0.062 & 22.6 & 0.018 & 0.077 & 0.131 & 0.8 & - & - & - & - & - & - \\
\hline T. rossicum & 11.7 & 9.1 & - & 0.016 & 0.025 & 0.049 & 15.5 & 0.030 & 0.012 & 0.113 & - & - & - & - & 0.8 & - & - \\
\hline H. 'pseudoharzianum' & 11.2 & 7.8 & - & 0.037 & 0.016 & 0.025 & 16.1 & 0.012 & 0.137 & 0.012 & - & - & - & - & - & - & - \\
\hline T. harzianum sensu stricto & 7.5 & 11 & 0.045 & 0.025 & 0.029 & 0.012 & 2.4 & 0.024 & - & - & - & - & - & - & - & - & - \\
\hline T. longibrachiatum $-H$. orientalis & 3.6 & 5 & - & 0.025 & 0.008 & 0.016 & 1.8 & 0.006 & 0.006 & 0.006 & - & - & - & - & - & 0.9 & - \\
\hline H. alni & 1.9 & - & - & - & - & - & 4.8 & - & 0.048 & - & - & - & - & - & - & - & - \\
\hline T. pleuroticola & 1.9 & 2.5 & - & 0.025 & - & - & 1.2 & - & 0.012 & - & - & - & - & - & - & - & - \\
\hline T. cerinum & 1.2 & - & - & - & - & - & 3.0 & - & 0.018 & 0.012 & - & - & - & - & - & - & - \\
\hline T. brevicompactum & 1.0 & 0.8 & - & - & - & 0.008 & 1.2 & - & 0.006 & 0.006 & 0.9 & 0.8 & - & - & - & - & -0.8 \\
\hline H. schweinitzii & 1.0 & 1 & - & 0.004 & 0.004 & 0.004 & 0.6 & - & 0.006 & - & - & - & -0.8 & - & - & - & - \\
\hline Trichoderma sp. C.P.K. 2974 & 0.5 & - & - & - & - & - & 1.2 & - & 0.006 & 0.006 & - & - & - & - & - & - & - \\
\hline $\begin{array}{l}\text { Trichoderma sp. MOTU 2B } 48 \text { section } \\
\text { Trichoderma }\end{array}$ & 0.5 & - & - & - & - & - & 1.2 & - & 0.012 & - & - & - & - & - & - & - & - \\
\hline H. pachybasioides & 0.5 & 0.8 & - & - & 0.008 & - & - & - & - & - & - & - & - & - & - & - & - \\
\hline $\begin{array}{l}\text { Trichoderma sp. MOTU 1A } 64 \text { section } \\
\text { Longibrachiatum }\end{array}$ & 0.5 & 0.8 & - & 0.008 & - & - & - & - & - & - & - & - & - & - & - & - & - \\
\hline H. atroviridis & 0.2 & 0.4 & - & 0.004 & - & - & - & - & - & - & - & - & - & - & - & - & - \\
\hline H. virens & 0.2 & 0.4 & - & 0.004 & - & - & - & - & - & - & - & - & - & - & - & - & - \\
\hline Total & 100 & 100 & & & & & 100 & & & & & & & & & & \\
\hline Diversity index & 1.0 & 0.8 & 0.15 & 0.77 & 0.34 & 0.62 & 0.8 & 0.46 & 0.92 & 0.62 & 0.5 & 0.5 & -0.7 & -0.5 & 0.0 & 0.4 & -0.3 \\
\hline
\end{tabular}

${ }^{*}$ The size of each horizon-specific clone library is given in parentheses. 
ecosystem. In total, soils in both forest sites supported the community of at least 13 co-existing Hypocrea/Trichoderma species, although these communities were unequal in two locations.

\section{The highest Hypocrea/Trichoderma diversity was detected in the moist horizon of aspen forest soil that has a low root density and poor carbon content}

The analysis of Hypocrea/Trichoderma species distribution in the vertical soil profile showed that T. asperellum was most abundant in the soil litter layer of the beech forest $(82 \%)$ and also dominated in A and B horizons (53 and $59 \%$, respectively) while in horizon $\mathrm{C}$ it was only the third most abundant taxon (16\%). A similar distribution pattern was observed in the aspen forest soil (Table 3). The correlation analysis showed a significant negative correlation of $T$. asperellum abundance with $\mathrm{pH}$ values (Table 3) that decreases with depth, indicating that this species is associated with either the soil litter layer or the upper organic horizon A.

The distribution of the next most frequent species $H$. pachypallida in the vertical soil profile is inversely proportional to that of T. asperellum (Fig. 1, Table 3); in the beech forest soil it dominated the deepest $\mathrm{C}$ horizon $(30 \%)$ and was not detected in others, while in the aspen forest it was found in all horizons but with increasing frequency from top to bottom. The significant correlation of its occurrence with the horizon (Table 3) but not with other factors (carbon content, $\mathrm{pH}$ and depth) suggests the presence of yet another parameter which controls the distribution of this species and which was not monitored in this study.

T. rossicum, one of the co-dominant species in both locations, is also more frequent in the deeper soil horizons showing a significant positive correlation with the $\mathrm{C} / \mathrm{N}$ ratio (Table 3). MOTUs of the $T$. longibrachiatum $-H$. orientalis species pair were the most frequent in the A horizon of the beech soil profile which has the highest root density $(r=0.8, P<0.05)$. No correlations were detected for $H$. 'pseudoharzianum' and T. harzianum sensu stricto.

The highest diversity of Hypocrea/Trichoderma (12 coexisting species) was found in the moist $\mathrm{BC}$ horizon of the aspen forest soil which has a low root density and the lowest carbon content. The next most diverse infrageneric community (10 species) was in the topsoil horizon A in the beech forest, which has the highest root density. As these communities share six species but have no similar frequencies, this indicates that no significant correlation between species richness and soil properties were detected.

We applied several statistical techniques to reveal possible correlations between the distribution of MOTUs from different species. The product-moment correlation analysis confirmed the significant $(P<0.05)$ negative correlation between $T$. asperellum on one hand and $H$. pachypallida and T. rossicum on the other (Supplementary Table S1, available with the online version of this paper). No other significant correlation between dominant (co- and sub-) species was revealed, suggesting that these species have different responses to the microecological conditions.

\section{qPCR confirms the vertical distribution of T. asperellum}

In order to have a second means of testing species distribution in the soil profile, we designed species-specific primers for qPCR based on the polymorphic fragment of the tefl gene. Although 40 primers were tested (see Methods for details), only those for T. asperellum and $H$. schweinitzii were shown to be highly selective and efficient when applied to soil DNA extracts (Table 2, Fig. 2). Using these, we detected a higher abundance of $T$. asperellum and a relatively small amount of $H$. schweinitzii DNA in all seven samples, which is in accordance with the metagenomic data. It was also possible to detect a reduction in $T$. asperellum biomass with depth while the distribution of $H$. schweinitzii remained constant.

\section{Hypocrea/Trichoderma species respond in a unique way to the presence of their tribal relatives}

We show that several common Hypocrea/Trichoderma species may co-exist in one horizon of a floodplain soil. As many of these species are known for their mycoparasitic activity (for example $T$. asperellum, $H$. atroviridis, $T$. rossicum, T. harzianum sensu stricto, $H$. 'pseudoharzianum' or $T$. pleuroticola) they may also compete with their tribal relatives or, alternatively, they may behave synergistically. In order to determine this, we randomly selected 11 strains available in the collection of industrial micro-organisms from Vienna University of Technology (TUCIM) that were of temperate origin and represented species that were detected as one community in this study. We also included the ex-type strain of $T$. stromaticum (teleomorph $H$. stromatica) as a member of a tropical ecosystem (isolated associated with Moniliophthora perniciosa, a causative agent of 'witches' broom' of Theobroma cacao; Samuels et al., 2000) because this species is closely related to $T$. rossicum (Table 4). Conidia of each of these species were grown in the presence of culture extracts of all other species in pair-wise combinations (Fig. 3). The results show that the strains express strongly differentiated responses to the presence of culture extracts from their close tribal relatives. Strains of $T$. asperellum and $H$. atoviridis (both belonging to section Trichoderma), which have the fastest growth rate (Supplementary Fig. S3, available with the online version of this paper), showed a strong inhibition (up to $90 \%$ ) of their mycelial growth rate in the presence of culture extracts of any other species (Fig. 4a). Two other closely related strains ( $T$. longibrachiatum and $H$. schweinitzii, section Longbrachiatum) showed nearly no response to the presence of any other culture extract. H. stromatica and T. rossicum (both members of the phylogenetic Stromaticum clade) 

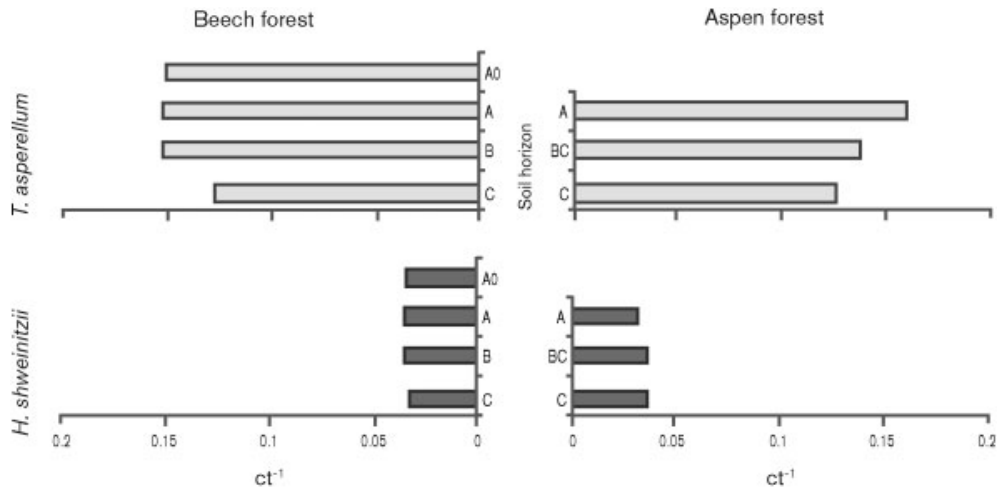

\begin{abstract}
Fig. 2. Results of the qPCR analysis based on species-specific tef1 primers developed for $T$. asperellum and $H$. schweinitzii. As the efficiency of primers binding the environmental (soil) DNA was slightly different between these species, only a semiquantitative comparison is possible. The number of threshold cycles $/ 1$ $\left(\mathrm{ct}^{-1}\right.$ ) corresponds to the abundance of the target DNA in the sample.
\end{abstract}

differed in their response to other fungi: the first species was either insensitive or slightly inhibited $(\sim 20 \%)$ while the latter was significantly stimulated by the presence of culture extracts of T. asperellum (20\%), T. stromaticum, $H$. 'pseudoharzianum' and T. brevicompactum (50\% each). The most versatile response was detected for strains representing the Harzianum-Catoptron clade: in general these species are either insensitive to culture filtrates from other fungi ( $T$. pleuroticola) or their growth is strongly stimulated. Thus, $H$. alni formed $180 \%$ of its biomass in the presence of culture extract of $T$. asperellum and $85 \%$ in the presence of $H$. atroviridis (Fig. 4a). Only a few cases of growth inhibition were found for this group: $H$. 'pseudoharzianum' grew poorly in the presence of culture extract of $H$. atroviridis, indicating competitive relations between these strains. $T$. brevicompactum was slightly inhibited by all other cultures except T. asperellum and T. cerinum, which caused 25 and $28 \%$ acceleration, respectively.

The presence of culture extracts of tribal relatives also significantly influenced the conidiation (Figs 3 and $4 \mathrm{~b}$ ), whereas the conidiation of $T$. asperellum, whose growth was inhibited by presence of all other culture filtrates, was completely insensitive to the extracts of all other fungi (Fig. 4b). H. atroviridis, intensively conidiating in the control experiment, almost stopped producing conidia in the presence of T. longibrachiatum, $H$. alni and $H$. 'pseudoharzianum'. In contrast, the poorly sporulating $T$. rossicum produced abundant conidia in the presence of nearly all other culture extracts except for that of $H$. alni. Many strains showed a versatile response ranging from suppression to stimulation of conidiation ( $H$. 'pseudoharzianum', T. pleuroticola, T. brevicompactum; Fig. 4b).

Statistical analysis revealed only a few cases of significant correlation $(P<0.05)$ between the effects of tribal relatives on growth and conidiation respectively (Supplementary Table S2, available with the online version of this paper). The majority of the strains respond in a unique way to the presence of the culture extracts of other Hypocreal Trichoderma. Similarly, the effects on growth and conidiation were looked at, positive correlations were only seen for $H$. alni $(r=0.59)$ and $H$. atroviridis $(r=0.62)$ and there was a negative correlation for $T$. harzianum sensu stricto, indicating that these processes are differently controlled in every Hypocrea/Trichoderma community.

\section{DISCUSSION}

To study the generic community of Hypocrea/Trichoderma in soil we selected a riparian forest in the River Danube National Park. This ecosystem is unique as it still resembles the original European river floodplain landscape free from

Table 4. Strains of Hypocrea/Trichoderma selected for in vitro modelling of tribal interactions

\begin{tabular}{|llll|}
\hline Species & \multicolumn{1}{c}{ Strain } & Origin & ITS1 and 2 GenBank accession no. \\
\hline T. asperellum & C.P.K. 820, CBS 433.97 ex-type & USA & GQ495671 \\
H. atroviridis & C.P.K. 2107, SzMC 3107 & Hungary & GU111561 \\
H. stromatica & C.P.K. 386, CBS101865 ex-type & Brazil & FJ442675 \\
T. rossicum & C.P.K. 889, MA 2480 & Austria & AJ507082 \\
T. harzianum sensu stricto & C.P.K. 1426 & Russia & GU111562 \\
H. pseudoharzianum & C.P.K. 2973 & Austria & GU111563 \\
T. cerinum & C.P.K. 3034 & Austria & GU111564 \\
H. alni & C.P.K. 2657, UNISS 10-16 & Italy & EF488139 \\
T. pleuroticola & C.P.K. 2104, CBS 121145 & Hungary & EF392794 \\
T. brevicompactum & C.P.K. 323, MA 3295 & USA & AY324173/AY324183 \\
T. longibrachiatum & C.P.K. 2062, CECT 2412 & UK & EU401572 \\
H. schweinitzii & C.P.K. 3619 & Russia & GU111565 \\
\hline
\end{tabular}



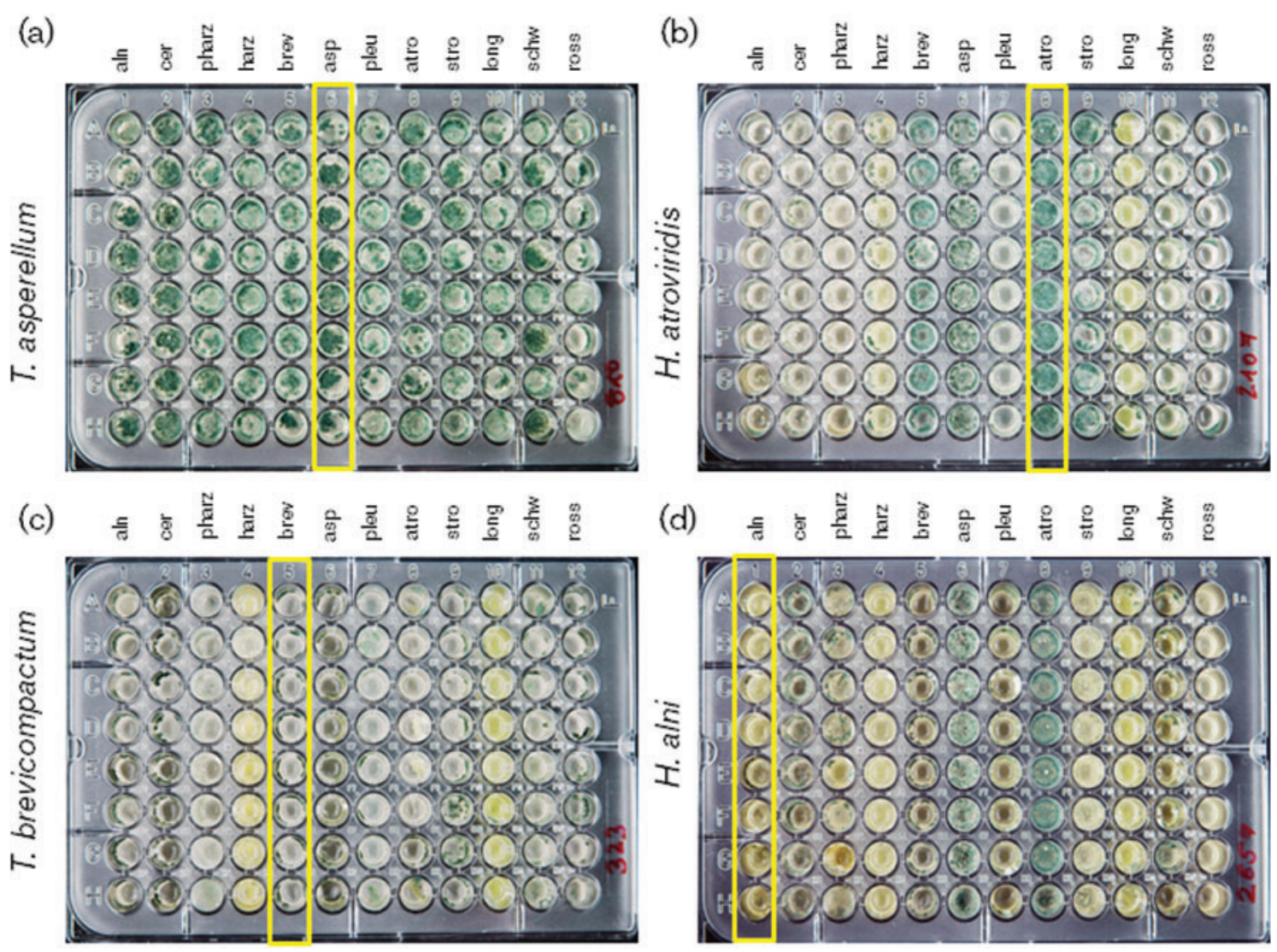

\begin{abstract}
Fig. 3. Selected examples of four 96-well microplates inoculated with spores of $T$. asperellum (a), $H$. atroviridis (b), $T$. brevicompactum (c) and $H$. alni (d) after $192 \mathrm{~h}$ incubation in darkness at $25^{\circ} \mathrm{C}$. Vertical columns correspond to repeated applications of culture extracts of $H$. alni (aln), T. cerinum (cer), H. 'pseudoharzianum' (pharz), T. harzianum (harz), T. brevicompactum (brev), T. asperellum (asp), T. pleuroticola (pleu), H. atroviridis (atro), H. stromatica (stro), T. longibrachiatum (long), H. schweinitzii (schw) and T. rossicum (ross), as indicated in Table 4. Control cases, when cultures were grown on their own culture extracts, are boxed.
\end{abstract}

anthropogenic loadings (Wuczkowski et al., 2003). The forest is characterized by high biodiversity, including several otherwise rare plant species (Tockner et al., 1998).

\section{Temperate soil supports a limited diversity of highly opportunistic Hypocrea/Trichoderma spp.}

Although the biodiversity of higher fungi is considered to be largely unknown (Hawksworth, 1991), and studies using cultivation-independent methods should thus result in the identification of a high percentage of unknown taxa, this is not the case with Hypocrea/Trichoderma. Our data suggest that, at least in soils of temperate climate, there is almost no hidden diversity of Hypocrea/Trichoderma: among 411 MOTUs, 407 were safely attributed to 15 existing species or to putative novel taxa that have previously been sampled. The diversity of Hypocrea/Trichoderma in Europe consists of at least 75 holomorphic species (Jaklitsch, 2009) and 1020 anamorphic species (see Introduction), approaching 100 taxa. We found only a minor portion of the potentially expected diversity (roughly 15\%) which is in agreement with the previous hypothesis that soil itself is not the primary ecological niche for the genus (Druzhinina et al., 2011). A similar outcome was also obtained by using the pioneering metagenomic studies of Hypocrea/Trichoderma. Hagn et al. (2007) used the ITS1 fragment and found only about 12 species in arable soil. Meincke et al. (2010) used partial ITS1 and 2 sequences and detected about 20 Hypocrea/Trichoderma taxa in the rhizosphere of Solanum tuberosum, although no positive species identifications were made. This view is also in agreement with studies that applied high-throughput sequencing to reveal the actual in situ diversity of higher fungi in soil; in these studies, Hypocrea/Trichoderma MOTUs were only found in minor proportions compared with other dominant groups of Ascomycota (Buée et al., 2009; Lim et al., 2010).

The perception of Hypocrea/Trichoderma as a common soil fungus is based on the abundant isolates from soil samples worldwide. However, the qualitative analysis of the diversity revealed in such samples shows dominance by the same 15-20 highly opportunistic species such as T. asperellum, T. 

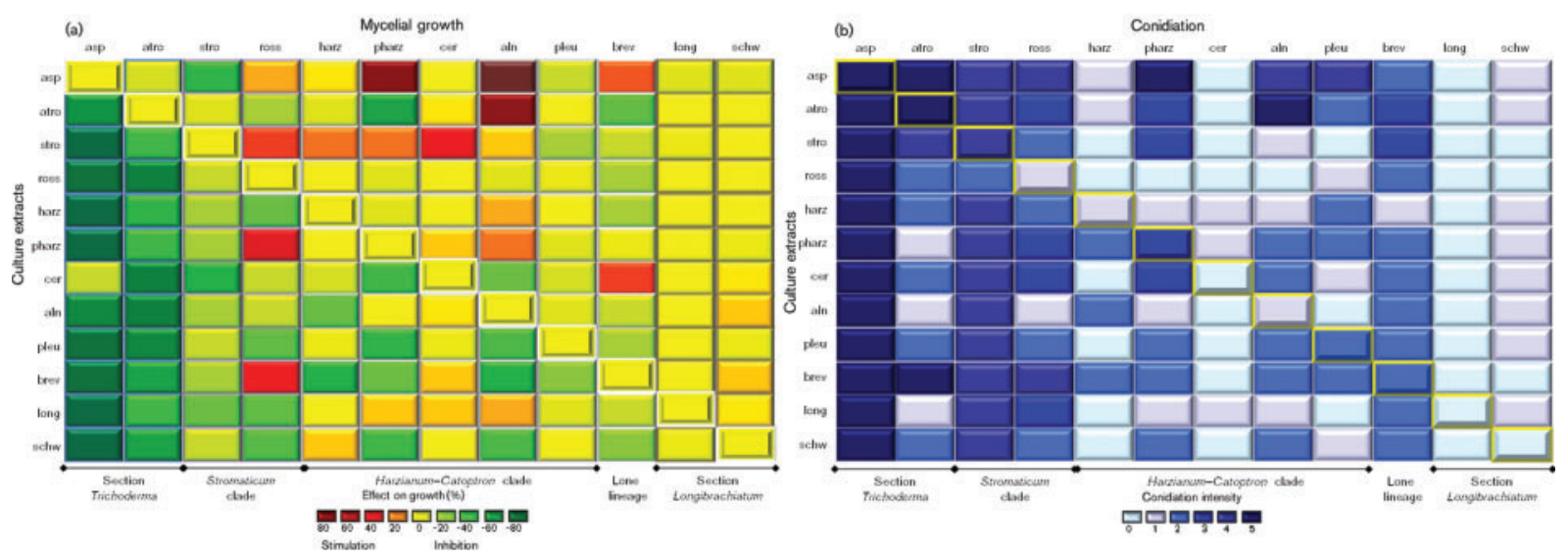

Fig. 4. Discrete colour plots showing the results of a pair-wise modelling of Hypocrea/Trichoderma communities when selected strains were grown in the presence of a culture extract of any other strain in the experiment. Diagonal values correspond to controls when cultures were grown on their own culture extracts. (a) Effect on growth shown as \% growth inhibition (greens) or growth stimulation (reds). Values are normalized to the control. (b) Effect on conidiation expressed in a nominative scale developed by Friedl et al. (2008). Complete absence of conidiophores and conidia (0), formation of immature pustules without mature conidia (1) and four levels of conidiation intensity (2-5) from weak diffuse sporulation (2) up to the development of a thick conidial mat covering the whole well (5). Values are not normalized to the control. Rows/columns are labelled as described in the legend for Fig. 3.

asperelloides, T. cf. harzianum, T. hamatum, T. atroviride, T. virens, T. longibrachiatum, T. gamsii, T. citrinoviride, T. koningiopsis, T. spirale, T. koningii complex etc. (see http:// www.isth.info/materials/topic.php?material_id=42 for details), which probably obtained the ability for saprotrophic growth in soil due to their general outstanding opportunistic potential, as suggested based on the genomes of $H$. atroviridis and $H$. virens (Druzhinina et al., 2011; Kubicek et al., 2011). Moreover, the antifungal activity of Hypocrea/Trichoderma spp. favours their detection as they are able to suppress other fungi. The view of soil as the main determinant of the Hypocrea/Trichoderma ecological niche is not supported.

The qualitative composition of the Hypocrea/Trichoderma community reveals that soil is inhabited by highly opportunistic species with cosmopolitan distributions as all taxa, except the three MOTUs of putative novel species, are common and have been identified from multiple isolates from numerous substrata (including soil) from temperate ecosystems worldwide.

\section{The occurrence of Hypocrea/Trichoderma species in different soil profiles is not determined by root density}

The PCR efficiency with Hypocrea/Trichoderma-specific primers was essentially higher in samples from the moist beech forest (all horizons except the litter layer $\mathrm{A} 0$ ) compared with those from the aspen site (Supplementary Fig. S1), while there was no visual difference between both sites when general fungal primers were used (data not shown). This finding indirectly suggests that the beech forest contains more Hypocrea/Trichoderma biomass than the aspen soil.
Not all species known to be abundant in this region have been detected in soil profiles. For instance, the most frequent teleomorphic Hypocrea/Trichoderma species in Central Europe, H. minutispora (Jaklitsch, 2009), was not identified in our study at all. Despite this, H. minutispora was found in abundance in air samples from nearly the same region (within a few $\mathrm{km}^{2}$ ) using the same PCR methodology as here (M. A. Friedl, I. S. Druzhinina, unpublished data), thus supporting the assumption that there was no methodical bias in our experimental procedures. Similarly, many other very common local Hypocrea species (e.g. $H$. viridescens, $H$. rufa, $H$. pulvinata, $H$. strictipilosa; Jaklitsch et al., 2006a, b; Overton et al., 2006) were not detected in the Danube floodplain soils, indicating that there may be other ecological niches for their anamorphic stages.

The observed distribution of MOTUs in the vertical soil profile also suggests the existence of ecological factors that determine the proliferation of Trichoderma. T. asperellum, which was the dominant species in this study, was reproducibly associated with upper soil horizons, but its abundance did not correlate with the carbon and nitrogen content of the soil or $\mathrm{pH}$ of the soil solution. Also, the highest number of MOTUs for T. asperellum was found in the root-free A0 litter layer of the beech site, and we therefore suspect that the rhizosphere is not its prime habitat. However, it might be that the species is following other fungi that are highly abundant in soil litter and upper soil horizons. In contrast with that, H. pachypallida and $T$. rossicum were almost exclusively detected in the deepest soil horizons characterized by the sufficient organic carbon and the nearly complete absence of plant roots. Moreover, these species should be capable of growing well under 
conditions of nitrogen starvation as the amount of nitrogen in their habitat is one order of magnitude lower than that in the surface soil. Both the high species richness of the deepest mineral soil horizons (eight species in each sampling site) and their unique species compositions compared with upper soil layers suggest competitive relations between tribal relatives (and/or with other mycoand microbionts) rather than their associations with abiotic characteristics of these soil horizons.

The limited diversity of Hypocrea/Trichoderma in the studied soils may be attributed to the relatively high $\mathrm{pH}$ values (around 8) which could potentially prevent the development of other species. However, the same cosmopolitan and opportunistic species also dominated more acidic soils in Sardinia ( $\mathrm{pH}$ 5; Migheli et al., 2009) and were present in rhizospheric soil of Coffea arabica in Ethiopian highland forest ( $\mathrm{pH} 5.5$; Mulaw et al., 2010), suggesting that this is not the controller of the diversity.

\section{In situ diversity confirms the sympatric speciation within $T$. harzianum sensu lato and related taxa}

In previous studies that used cultivation-dependent methods to quantify Hypocrea/Trichoderma in various habitats, T. harzianum sensu lato represented the most dominant species (Druzhinina et al., 2005; Migheli et al., 2009; Zachow et al., 2009; Druzhinina et al., 2010b, for further references). In this study, we also detected a remarkable diversity of genetically sibling species from the Harzianum-Catoptron clade (Chaverri et al., 2003; Druzhinina et al., 2010b) in nearly all soil samples. Interestingly, in all mineral soil horizons of the beech forest site, T. harzianum sensu stricto coexisted with a member of $H$. 'pseudoharzianum' (Druzhinina et al., 2010b), while in the aspen forest site, the latter was found together with other members of the Harzianum-Catoptron clade: T. cerinum, T. pleuroticola and H. alni. This finding suggests the sympatric speciation of $T$. harzianum sensu stricto and $H$. 'pseudoharzianum' (Druzhinina et al., $2010 \mathrm{~b}$ ) which is also proposed for other pairs of sister species in the genus Hypocrea/Trichoderma, such as $H$. jecorina and T. parareesei (Druzhinina et al., 2010a, Atanasova et al., 2010) or T. longibrachiatum and $H$. orientalis (Druzhinina et al., 2008). It is common to argue against the assignment of sympatric speciation modes to fungi as, although they may be distributed in overlapping ranges, they can occupy different microhabitats in those areas and therefore may still be spatially isolated (Burnett, 2003). Our findings show the non-random presence of MOTUs attributed to both T. harzianum sensu stricto and $H$. 'pseudoharzianum' in at least four soil habitats.

\section{Hypocrea/Trichoderma species express versatile effects on the presence of tribal relatives}

In order to reconstruct the possible interactions between Hypocrea/Trichoderma species occurring in the same soil horizon, we selected a sample set of model strains (Table 4) and tested the effect of a fresh culture extract of one strain on the growth of the other in a pair-wise manner. $T$. asperellum and $H$. atroviridis were essentially inhibited by the presence of other taxa (up to $80 \%$ ). However, these species initially had faster growth rates of nearly twofold compared with others in the same experimental conditions (see Supplementary Data). Therefore, the inhibition put them in the growth rate range of all other species rather than stopping their development. These data suggest that when the fungus is able to accelerate its growth in the absence of direct competitors, it possesses a strong opportunistic potential to occupy a vacant ecological niche.

The true cases of growth inhibition were, nevertheless, detected when, for example, $H$. 'pseudoharzianum' grew very little on culture extracts of $H$. atroviridis. Several cases of strong stimulation of mycelial growth have been also observed. It is notable that the mycelial growth of $H$. 'pseudoharzianum' was stimulated by T. asperellum which is in agreement with the metagenomic data. In the $\mathrm{BC}$ horizon of aspen soil, these two species were codominant (18 and 23 MOTUs, respectively); the other abundant species in this horizon was $H$. alni, which is, in turn, stimulated in the presence of culture extracts of the two former species. Thus, our metagenomic data are largely supported by in vitro interaction experiments.

\section{Hypocrea/Trichoderma species may facilitate each other's distribution}

Our data also show a strong change in the pattern of conidiation in the presence of culture extracts from other species, which does not correlate with alterations in mycelial growth. Sporulation of Trichoderma is known to be triggered by light (Betina \& Farkas, 1998). We have previously shown, however, that conidiation of $H$. atroviridis is strongly controlled by carbon metabolism while illumination plays only a secondary function in increasing the rate of conidia formation (Friedl et al., 2008). As our experiments were done in darkness and the culture filtrates were all obtained from growth of the strains on the same carbon source, the fact that conidiation was stimulated by culture filtrates of closely related strains is very interesting. Nemcovic et al. (2008) reported that conidiation in $H$. atroviridis was accompanied by the increased production of eight-carbon compounds 1-octen3-ol and its analogues 3-octanol and 3-octanone. When vapours of these compounds were applied individually to dark-grown colonies, even of other species, they elicited their conidiation at submicromolar concentrations. The authors concluded that the eight-carbon volatile organic compounds act as signalling molecules regulating development and mediating intercolony communication in Hypocrea/Trichoderma. In this study, we have not attempted to identify the particular stimulatory components; however, it is possible that some of the effects observed by us were due to such VOCs, but the multitude of bidirectional effects 
makes it rather unlikely that they are only due to a single component. In the present study we demonstrate that, for example, T. rossicum, which is most abundant in deep soil horizons (=darkness), is not able to produce conidia under control conditions, while it starts to sporulate in the presence of almost all other cultures. We therefore conclude that many Hypocrea/Trichoderma species inhabiting the same microecological niche not only compete with one another but are also able to act synergistically, accelerating the sensing of abiotic factors and thus facilitating each other's distribution. Such an assumption is in agreement with our metagenomic data.

\section{Biocontrol formulations may benefit from synergistic action of highly opportunistic Hypocrea/Trichoderma spp.}

A community of highly opportunistic Hypocrea/Trichoderma has been detected in previous cultivation-dependent studies. Migheli et al. (2009) showed that among 16 species isolated from highly disturbed non-rhizosphere soils in Sardinia (Italy) H. 'pseudoharzianum, T. spirale, T. gamsii, T. hamatum or H. koningiopsis consistently co-occurred. A similar result was shown in the pioneering metagenomic study on Trichoderma in agricultural soils when representatives of the Harzianum-Catoptron and Hamatum clades, which cover species known for their antagonistic potential, were recovered from the same samples (Hagn et al., 2007). Zachow et al. (2009) applied metagenomic methods and traditional cultivation techniques to characterize the diversity of fungi in the rhizosphere of endemic plant species of Tenerife (Canary Islands) and showed the co-existence of extraordinarily highly antagonistic strains of Hypocrea/Trichoderma.

From a practical point of view, this demonstrates that the knowledge about infrageneric communities and interactions will be important for screening Hypocrea/Trichoderma strains to be used for the biological control of soil-borne plant-pathogenic fungi. Several strains showing synergism with one another may be combined in certain biocontrol formulations, while on the other hand, the indigenous Hypocrea/Trichoderma should not have antagonistic properties against the introduced biocontrol strain(s).

In this study, we investigated one of the last remaining undisturbed ecosystems in Central Europe. However, the diversity found in the national park largely resembles the Hypocrea/Trichoderma species composition in disturbed and agricultural soils (Migheli et al., 2009; Hagn et al., 2007). This finding indicates that the local highly opportunistic species (from those listed above) should be among the major taxa screened for the best Trichoderma biocontrol strains.

\section{Both ITS rRNA and tef1 phylogenetic markers have limited applicability for in situ diversity studies using the high-throughput methods}

Hagn et al. (2007) designed Hypocrea/Trichoderma-specific primers for the ITS1 fragment of the rRNA gene cluster.
However, later studies showed that ITS1 is not sufficiently diagnostic as many species share the same allele. Meincke et al. (2010) set up genus-specific primers with the reverse primer located in a still polymorphic and indel-rich area of ITS2 30 bp upstream of the last genus-specific hallmark, which makes several species undetectable. The six Trirev primers presented in this study amplify the entire diagnostic region of ITS1 and 2 of all members of the genus. We have demonstrated the high specificity and selectivity of these primers as no MOTUs belonging to other fungi were recovered, but the two novel alleles of ITS1 and 2 were detected.

Hoyos-Carvajal et al. (2009) asserted the presence of paralogous copies of ITS1 and 2 in some Hypocreal Trichoderma species. In order to test this, we constructed a clone library for randomly selected strains of $T$. asperellum $(n=30)$ and found only one allele (data not shown) of ITS1 and 2, confirming the absence of different alleles within a single genome.

The applicability of ITS1 and 2 for larger metagenomic studies using high-throughput sequencing methods remains questionable. On one hand, ITS-based quantification of species abundance in environmental samples will depend on the number of ITS copies in the respective genome, which may vary between different species. Furthermore, a growing number of Hypocrea/Trichoderma species share the same ITS allele making these taxa indistinguishable by this locus (Samuels et al., 2006a, b; Jaklitsch et al., 2006b; Druzhinina et al., 2008; Atanasova et al., 2010). Another disadvantage of ITS1 and 2 comes from the fact that these sequences are not appropriate for the design of species-specific $\mathrm{QPCR}$ primers, as most of their diagnostic zones are surrounded by long mononucleotide stretches and/or have an intolerable GC content (L. Bodrossy \& I. S. Druzhinina, unpublished data). Gazis et al. (2011) compared the three communities of endophytic fungi and revealed that ITS alone usually underestimates the number of taxa predicted by other loci. Sequences for the highly polymorphic fourth large intron of the tef 1 gene are also available for the majority of Hypocrea/ Trichoderma species, making it a good alternative to ITS1 and 2. This gene has a single copy in the genome and therefore becomes appropriate for quantitative assessments. However, the current public databases of Hypocreales tef 1 sequences do not yet allow the design of genus-specific primers. In this study, we attempted to develop speciesspecific tef1 primers for those taxa that we either detected among MOTUs or could expect to be present in temperate soils (based, for example, on Jaklitsch, 2009, 2011). In vitro tests showed that only two out of 40 in silico-designed oligonucleotides are selective for target taxa, while others demonstrated unspecific affinity to the DNA of non-target species, probably due to the polymorphic secondary structures of the fragment. These results suggest that the tef 1 intron alone is also not appropriate for a large-scale metagenomic analysis of the genus due to its hypervariablity. The applicability of more conserved markers such as rpb2 or chi18-5 is currently being tested in our laboratory. 


\section{ACKNOWLEDGEMENTS}

This work was supported by the Austrian Science Fund (FWF): project number P-17859 to I.S.D. The authors are grateful to Benigno Aquino and Lea Atanasova (Vienna University of Technology, Austria) for their laboratory assistance, to Vera Terekhova (Moscow State University, Russia) for advice on soil analysis and to Gottfried Haubenberger (Nationalpark Donau-Auen, Austria) for his help during the sampling procedure. The authors are very thankful to Christian P. Kubicek (Vienna University of Technology, Austria) for critical reading and discussion of the manuscript.

\section{REFERENCES}

Atanasova, L., Jaklitsch, W. M., Komoń-Zelazowska, M., Kubicek, C. P. \& Druzhinina, I. S. (2010). Clonal species Trichoderma parareesei sp. nov. likely resembles the ancestor of the cellulase producer Hypocrea jecorina/T. reesei. Appl Environ Microbiol 76, 7259-7267.

Batjes, N. H. (1996). Total carbon and nitrogen in the soils of the world. Eur J Soil Sci 47, 151-163.

Betina, V. \& Farkas, V. (1998). Sporulation and light-induced development in Trichoderma. In Trichoderma \& Gliocladium, vol. 1, pp. 75-94. Edited by G. E. Harman \& C. P. Kubicek. London: Taylor \& Francis.

Buée, M., Reich, M., Murat, C., Morin, E., Nilsson, R. H., Uroz, S. \& Martin, F. (2009). 454 Pyrosequencing analyses of forest soils reveal an unexpectedly high fungal diversity. New Phytol 184, 449-456.

Burnett, J. (2003). Fungal Populations and Species. Oxford: University Press.

Chaverri, P., Castlebury, L. A., Samuels, G. J. \& Geiser, D. M. (2003). Multilocus phylogenetic structure within the Trichoderma harzianum/ Hypocrea lixii complex. Mol Phylogenet Evol 27, 302-313.

Colwell, R. K. (2005). EstimateS: statistical estimation of species richness and shared species from samples (version 7.5). User's guide and application, http://viceroy.eeb.uconn.edu/estimates

Druzhinina, I. S., Kopchinskiy, A. G., Komoń, M., Bissett, J., Szakacs, G. \& Kubicek, C. P. (2005). An oligonucleotide barcode for species identification in Trichoderma and Hypocrea. Fungal Genet Biol 42, 813828 .

Druzhinina, I. S., Kopchinskiy, A. G. \& Kubicek, C. P. (2006). The first 100 Trichoderma species characterized by molecular data. Mycoscience 47, 55-64.

Druzhinina, I. S., Komoń-Zelazowska, M., Kredics, L., Hatvani, L., Antal, Z., Belayneh, T. \& Kubicek, C. P. (2008). Alternative reproductive strategies of Hypocrea orientalis and genetically close but clonal Trichoderma longibrachiatum, both capable of causing invasive mycoses of humans. Microbiology 154, 3447-3459.

Druzhinina, I. S., Komoń-Zelazowska, M., Atanasova, L., Seidl, V. \& Kubicek, C. P. (2010a). Evolution and ecophysiology of the industrial producer Hypocrea jecorina (Anamorph Trichoderma reesei) and a new sympatric agamospecies related to it. PLoS ONE 5, e9191.

Druzhinina, I. S., Kubicek, C. P., Komoń-Zelazowska, M., Mulaw, T. B. \& Bissett, J. (2010b). The Trichoderma harzianum demon: complex speciation history resulting in coexistence of hypothetical biological species, recent agamospecies and numerous relict lineages. BMC Evol Biol 10, 94.

Druzhinina, I. S., Seidl-Seiboth, V., Herrera-Estrella, A., Horwitz, B. A., Kenerley, C. M., Monte, E., Mukherjee, P. K., Zeilinger, S. Grigoriev, I. V. \& Kubicek, C. P. (2011). Trichoderma: the genomics of opportunistic success. Nat Rev Microbiol 9, 749-759.
FAO (1998). World Reference Base for Soil Resources. Rome: Food and Agriculture Organization of the United Nations.

Friedl, M. A., Kubicek, C. P. \& Druzhinina, I. S. (2008). Carbon source dependence and photostimulation of conidiation in Hypocrea atroviridis. Appl Environ Microbiol 74, 245-250.

Gazis, R., Rehner, S. \& Chaverri, P. (2011). Species delimitation in fungal endophyte diversity studies and its implications in ecological and biogeographic inferences. Mol Ecol 20, 3001-3013.

Hagn, A., Wallisch, S., Radl, V., Charles Munch, J. \& Schloter, M. (2007). A new cultivation independent approach to detect and monitor common Trichoderma species in soils. J Microbiol Methods 69, 86-92.

Harman, G. E., Howell, C. R., Viterbo, A., Chet, I. \& Lorito, M. (2004). Trichoderma species - opportunistic, avirulent plant symbionts. Nature Rev Microbiol 2, 43-56.

Hawksworth, D. L. (1991). The fungal dimension of biodiversity: magnitude, significance, and conservation. Mycol Res 95, 641-655.

Hoyos-Carvajal, L., Orduz, S. \& Bissett, J. (2009). Genetic and metabolic biodiversity of Trichoderma from Colombia and adjacent neotropic regions. Fungal Genet Biol 46, 615-631.

Jaklitsch, W. M. (2009). European species of Hypocrea Part I. The green-spored species. Stud Mycol 63, 1-91.

Jaklitsch, W. M. (2011). European species of Hypocrea. Part II: species with hyaline ascospores. Fungal Divers 48, 1-250.

Jaklitsch, W. M., Komon, M., Kubicek, C. P. \& Druzhinina, I. S. (2005). Hypocrea voglmayrii sp. nov. from the Austrian Alps represents a new phylogenetic clade in Hypocrea/Trichoderma. Mycologia 97, 13651378.

Jaklitsch, W. M., Komon, M., Kubicek, C. P. \& Druzhinina, I. S. (2006a). Hypocrea crystalligena sp. nov., a common European species with a white-spored Trichoderma anamorph. Mycologia 98, 499-513.

Jaklitsch, W. M., Samuels, G. J., Dodd, S. L., Lu, B.-S. \& Druzhinina, I. S. (2006b). Hypocrea rufa/Trichoderma viride: a reassessment, and description of five closely related species with and without warted conidia. Stud Mycol 56, 135-177.

Jaklitsch, W. M., Kubicek, C. P. \& Druzhinina, I. S. (2008). Three European species of Hypocrea with reddish brown stromata and green ascospores. Mycologia 100, 796-815.

Klein, D. \& Eveleigh, D. E. (1998). Ecology of Trichoderma. In Trichoderma \& Gliocladium, vol. 1, pp. 57-73. Edited by G. E. Harman \& C. P. Kubicek. London: Taylor \& Francis.

Komon-Zelazowska, M., Bissett, J., Zafari, D., Hatvani, L., Manczinger, L., Woo, S., Lorito, M., Kredics, L., Kubicek, C. P. \& Druzhinina, I. S. (2007). Genetically closely related but phenotypically divergent Trichoderma species cause green mold disease in oyster mushroom farms worldwide. Appl Environ Microbiol 73, 74157426.

Kopchinskiy, A. G., Komon, M., Kubicek, C. P. \& Druzhinina, I. S. (2005). TrichoвLAST: a multiloci database for Trichoderma and Hypocrea identification. Mycol Res 109, 658-660.

Kraus, G. F., Druzhinina, I. S., Gams, W., Bissett, J., Zafari, D., Szakacs, G., Koptchinski, A., Prillinger, H., Zare, R. \& Kubicek, C. P. (2004). Trichoderma brevicompactum sp. nov. Mycologia 96, 10591073.

Kubicek, C. P., Komon-Zelazowska, M. \& Druzhinina, I. S. (2008). Fungal genus Hypocrea/Trichoderma: from barcodes to biodiversity. J Zhejiang Univ Sci B 9, 753-763.

Kubicek, C. P., Herrera-Estrella, A., Seidl-Seiboth, V., Martinez, D. A., Druzhinina, I. S., Thon, M., Zeilinger, S., Casas-Flores, S., Horwitz, B. A. \& other authors (2011). Comparative genome sequence analysis 
underscores mycoparasitism as the ancestral life style of Trichoderma. Genome Biol 12, R40.

Lim, Y. W., Kim, B. K., Kim, C., Jung, H. S., Kim, B. S., Lee, J. H. \& Chun, J. (2010). Assessment of soil fungal communities using pyrosequencing. J Microbiol 48, 284-289.

Linhart, C. \& Shamir, R. (2005). The degenerate primer design problem: theory and applications. J Comput Biol 12, 431-456.

Lorito, M., Woo, S. L., Harman, G. E. \& Monte, E. (2010). Translational research on Trichoderma: from 'omics to the field. Annu Rev Phytopathol 48, 395-417.

Martinez, D., Berka, R. M., Henrissat, B., Saloheimo, M., Arvas, M., Baker, S. E., Chapman, J., Chertkov, O., Coutinho, P. M. \& other authors (2008). Genome sequencing and analysis of the biomassdegrading fungus Trichoderma reesei (syn. Hypocrea jecorina). Nat Biotechnol 26, 553-560.

Meincke, R., Weinert, N., Radl, V., Schloter, M., Smalla, K. \& Berg, G. (2010). Development of a molecular approach to describe the composition of Trichoderma communities. J Microbiol Methods 80, 63-69.

Migheli, Q., Balmas, V., Komoń-Zelazowska, M., Scherm, B., Fiori, S., Kopchinskiy, A. G., Kubicek, C. P. \& Druzhinina, I. S. (2009). Soils of a Mediterranean hot spot of biodiversity and endemism (Sardinia, Tyrrhenian Islands) are inhabited by pan-European, invasive species of Hypocrea/Trichoderma. Environ Microbiol 11, 35-46.

Mulaw, T. B., Kubicek, C. P. \& Druzhinina, I. S. (2010). The rhizosphere of Coffea arabica in its native highland forests of Ethiopia is associated with a distinguished diversity of Trichoderma. Diversity 2, 527-549.

Nemcovic, M., Jakubíková, L., Víden, I. \& Farkas, V. (2008). Induction of conidiation by endogenous volatile compounds in Trichoderma spp. FEMS Microbiol Lett 284, 231-236.

Nicholas, K. B. \& Nicholas, H. B., Jr (1997). Genedoc: a tool for editing and annotating multiple sequence alignments. http://www. psc.edu/biomed/genedoc.

Overton, B. E., Stewart, E. L., Geiser, D. M. \& Jaklitsch, W. M. (2006). Systematics of Hypocrea citrina and related taxa. Stud Mycol 56, 1-38.

Robertson, G. P., Coleman, D. C. \& Bledsoe, C. S. (1999). Standard Soil Methods for Long-Term Ecological Research. Oxford: Cambridge University press.

Rossmann, A. Y., Samuels, G. J., Rogerson, C. T. \& Lowen, R. (1999). Genera of Bionectriaceae, Hypocreaceae and Nectriaceae (Hypocreales, Ascomycetes). Stud Mycol 42, 1-83.
Samuels, G. J. (2005). Changes in taxonomy, occurrence of the sexual stage and ecology of Trichoderma spp. Phytopathology 96, 195220.

Samuels, G. J., Pardo-Schultheiss, R. A., Hebbar, K. P., Lumsden, R. D., Bastos, C. N., Costa, J. C. \& Bezerra, J. L. (2000). Trichoderma stromaticum sp. nov., a parasite of the cacao witches broom pathogen. Mycol Res 104, 760-764.

Samuels, G. J., Suarez, C., Solis, K., Holmes, K. A., Thomas, S. E., Ismaiel, A. \& Evans, H. C. (2006a). Trichoderma theobromicola and T. paucisporum: two new species isolated from cacao in South America. Mycol Res 110, 381-392.

Samuels, G. J., Dodd, S. L., Lu, B.-S., Petrini, O., Schroers, H. J. \& Druzhinina, I. S. (2006b). The Trichoderma koningii aggregate species. Stud Mycol 56, 67-133.

Samuels, G. J., Ismaiel, A., Bon, M.-C., De Respinis, S. \& Petrini, O. (2010). Trichoderma asperellum sensu lato consists of two cryptic species. Mycologia 102, 944-966.

Thompson, J. D., Gibson, T. J., Plewniak, F., Jeanmougin, F. \& Higgins, D. G. (1997). The CLUSTAL_X windows interface: flexible strategies for multiple sequence alignment aided by quality analysis tools. Nucleic Acids Res 25, 4876-4882.

Tockner, K., Schiemer, F. \& Ward, J. V. (1998). Conservation by restoration: the management concept for a river-floodplain system on the Danube river in Austria. Aquatic Conserv Mar Freshw Ecosyst 8, 71-86.

White, T. J., Bruns, T., Lee, S. \& Taylor, J. W. (1990). Amplification and direct sequencing of fungal ribosomal RNA genes for phylogenetics. In PCR protocols: a guide to methods and applications, pp. 315322. Edited by M. A. Innis, D. H. Gelfand, J. J. Sninsky \& T. J. White. New York: Academic Press.

Wuczkowski, M., Druzhinina, I., Gherbawy, Y., Klug, B., Prillinger, H. J. \& Kubicek, C. P. (2003). Species pattern and genetic diversity of Trichoderma in a mid-European, primeval floodplain-forest. Microbiol Res 158, 125-133.

Zachow, C., Berg, C., Müller, H., Meincke, R., Komon-Zelazowska, M., Druzhinina, I. S., Kubicek, C. P. \& Berg, G. (2009). Fungal diversity in the rhizosphere of endemic plant species of Tenerife (Canary Islands): relationship to vegetation zones and environmental factors. ISME J 3, 79-92.

Edited by: A. H. Herrera-Estrella 